\title{
TECHNOLOGY PORTFOLIO MANAGEMENT: OPTIMIZING INTERDEPENDENT PROJECTS OVER MULTIPLE TIME PERIODS
}

by

\section{Michael W. Dickinson}

B.S. Industrial Management, Oregon Institute of Technology, 1986

B.S. Mechanical Engineering Technology, Oregon Institute of Technology, 1986

Submitted to the Sloan School of Management and the

Department of Mechanical Engineering in partial fulfillment of the requirements for the degrees of

\section{Master of Science in Management and}

\section{Master of Science in Mechanical Engineering}

In conjunction with the Leaders for Manufacturing program at the Massachusetts Institute of Technology

May 1999

$$
\text { [inne, : } 90
$$

(C) Massachusetts Institute of Technology, 1999. All rights reserved

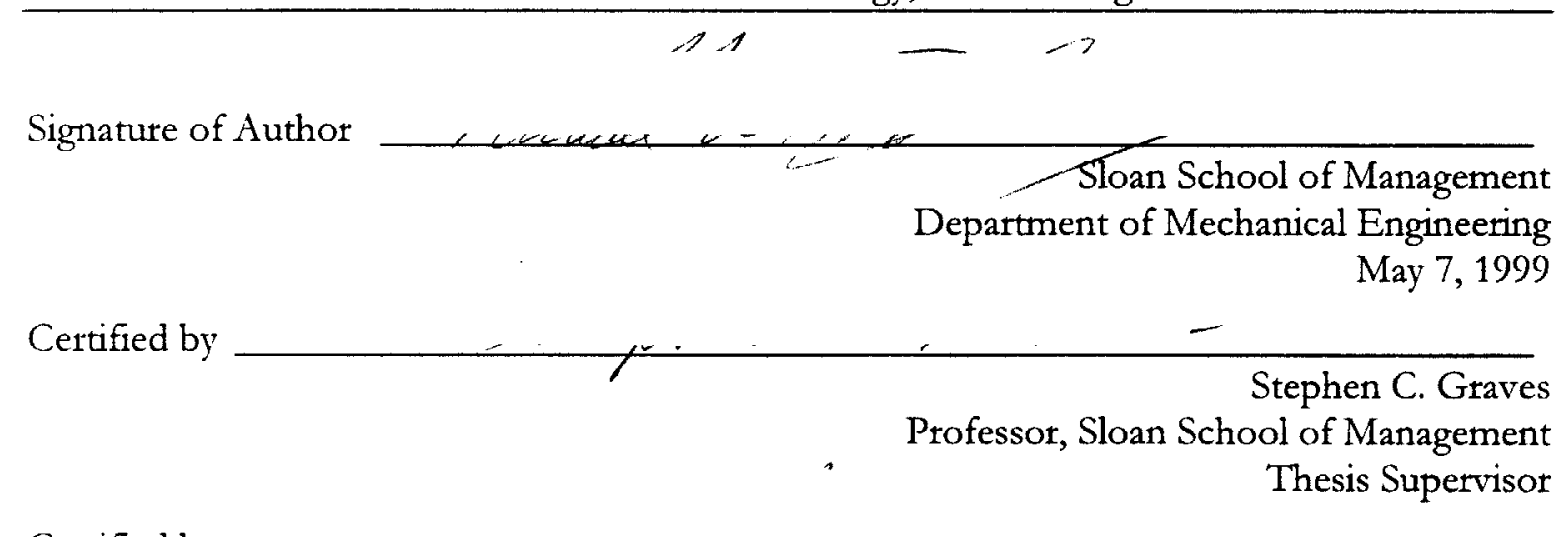

Certified by

Anna C. Thornton Assistant Professor of Mechanical Engineering $\neg$ a Thesis Supervisor

Accepted by

Lawrence S. Abeln

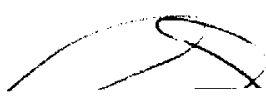
Director of Masters Program Sloan School of Management

Accepted by

Ain A. Sonin

Chairman, Department Committee on Graduate Students Department of Mechanical Engineering 


\title{
TECHNOLOGY PORTFOLIO MANAGEMENT: OPTIMIZING INTERDEPENDENT PROJECTS OVER MULTIPLE TIME PERIODS
}

by

\author{
Michael W. Dickinson \\ Submitted to the Sloan School of Management and the \\ Department of Mechanical Engineering in partial fulfillment of \\ the requirements for the degrees of \\ Master of Science in Management \\ and \\ Master of Science in Mechanical Engineering
}

\begin{abstract}
Many product development methodologies strategically allocate resources to create a portfolio of technology projects. These methodologies work well for projects that are predominantly independent of one another and occur in a common funding cycle. When the projects become interdependent, the complexity of optimizing even a moderate number of projects over a small number of objectives and constraints can become overwhelming. This paper presents an approach to account for and quantify the interdependencies of technology projects and explains how it was integrated into a non-linear, integer program model at The Boeing Company. The model evaluates if and when to start funding a project over a four year period. The effectiveness of each project in each year is influenced by whether or not the projects that it is dependent upon are also funded in that year. The funding choices influence the balance of identified risk in the portfolio, the support for designated categories of objectives, the cost and the estimated financial return of the portfolio. Optimizing the model identifies the funding strategy that maximizes the potential return subject to the spending and portfolio balance constraints. Once the "optimum" strategy is found, the model evaluates the impact of alternate portfolio strategies defined by the user.
\end{abstract}

Thesis Advisors:

Professor Stephen C. Graves, Sloan School of Management

Assistant Professor Anna C. Thornton, Department of Mechanical Engineering 


\section{ACKNOWLEDGMENTS}

The author gratefully wishes to acknowledge the support and resources made available to him through the Leaders for Manufacturing Program and The Boeing Company.

I would like to thank my thesis advisors, Professor Stephen C. Graves and Assistant Professor Anna C. Thornton for their insight and suggestions. They allowed me to explore several areas of interest, then helped focus my efforts into a thesis.

I would like to thank the many employees of the Boeing Company who shared their insights, ideas and challenges with me. I thank my sponsors Walt Gillette and Jeff Peace and my project manager Tom Mix for opening doors to other executives and training programs during my internship. In particular, I would like to thank Paul Kumler, Mike Teal, Rees Furbeck, Steve Holt, Sam Eldersveld, and Nicholas Walker for providing the majority of the knowledge that I acquired during this internship and for acting as my sounding board to help me to stay on track.

Most of all, I would like to thank my wife, Angie, for her patience, dedication and support. She helped to keep my priorities straight and made enormous sacrifices to help me achieve my goals. Her contributions as a wife, mom, coach, and friend have made this possible. 


\section{TABLE OF CONTENTS}

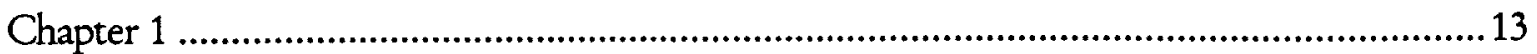

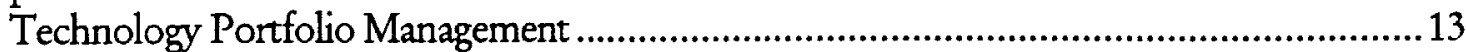

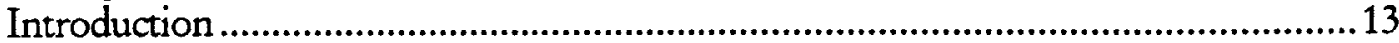

Portfolio Management in Practice ..........................................................................14

Classical Portfolio Tools .....................................................................................14

Mapping Portfolio Tools........................................................................................15

Mathematical Programming ..............................................................................16

Portfolio Management at Boeing.........................................................................17

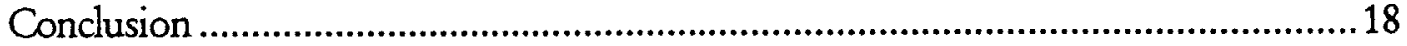

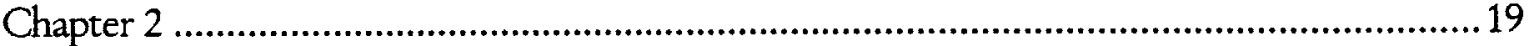

Portfolio Management in Boeing Commercial Airplanes...................................................19

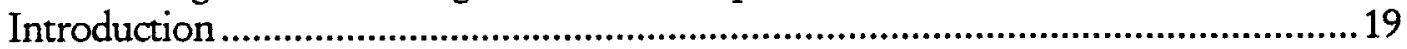

Airplane Creation Process Strategy ............................................................................19

ACPS Portfolio Management Process .......................................................................21

Financial Summary ......................................................................................2

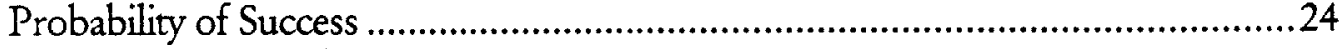

Project Interdependence ………….................................................................25

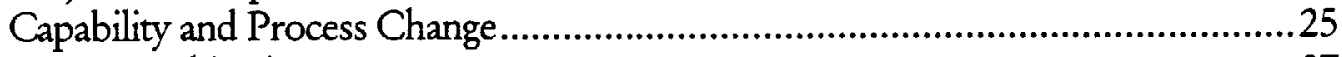

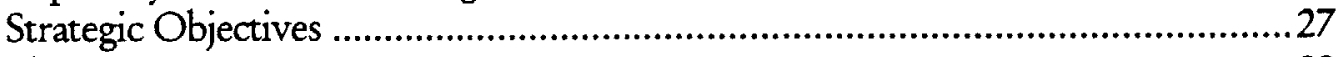

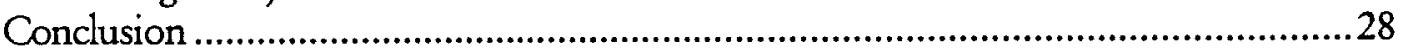



Optimizing Interdependent Projects over Multiple Time Periods......................................29

Research Overview ...............................................................................................29

The Dependency Matrix ............................................................................................

Applying the Dependency Matrix..........................................................................31

Sample Dependency Matrix .................................................................................32

Optimizing the Portfolio.............................................................................................34

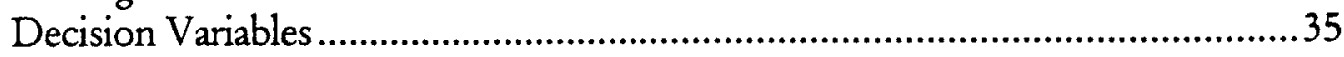

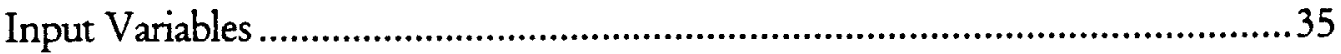

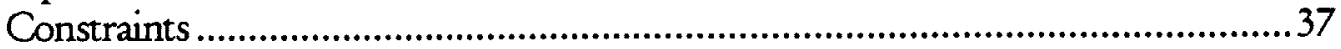

Model Objective Function ......................................................................................38

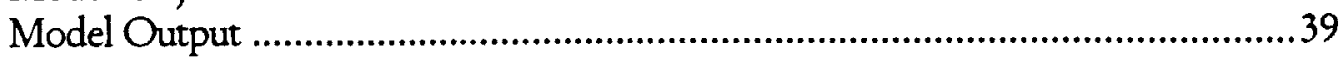

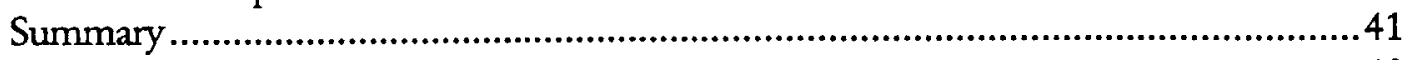



Applying the Dependency Matrix and the Optimization Model .......................................42

Introduction .......................................................................................................42

Solving and Applying the Optimization Model ...........................................................42

Observed Benefits ................................................................................................43

Potential Drawbacks ..........................................................................................45



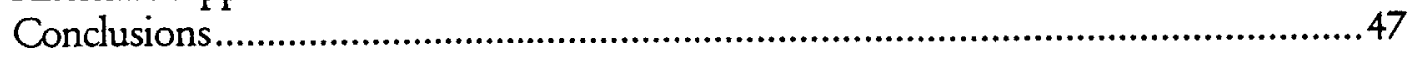




\section{LIST OF FIGURES}

Number

Figure 1 - ACPS Stage Gate Selection Funnel ......................................................................22

Figure 2 - Sample STP Financial Summary …………………...............................................24

Figure 3 - Sample Capability \& Process Change Matrix.........................................................26

Figure 4 - Sample Balance of the Strategic Objectives.............................................................27

Figure 5 - The Capability and Process Change Balance.............................................................39

Figure 6 - Balance of Support for Seven Objectives .............................................................40

Figure 7 - Sample Summary Financial Performance of the Portfolio.........................................41 


\section{GLOSSARY}

ACPS - Airplane Creation Process Strategy. A program at Boeing Commercial Airplanes to redesign the entire non-recurring product development process.

BCA - Boeing Commercial Airplanes. A Business Group of The Boeing Company.

NPV - Net Present Value. Discounted cash flows at a specified rate of return.

PMB - Portfolio Management Board. A cross-functional group responsible for managing the gated selection process and the portfolio of projects on the ACPS program.

STP - Situation Target Proposal. A standard format for submitting a project proposal to the Portfolio Management Board on the ACPS program. 
Chapter 1

"We precisely put the snart bomb through the renong window."

General Rod Kadish USAF

\section{TECHNOLOGY PORTFOLIO MANAGEMENT}

\section{Introduction}

The quotation above symbolizes the importance of technology portfolio management. An enterprise may have the best technology, but if it does not apply the technology in the proper way at the proper time in support of the overall objective, then it may yield little benefit. The concept of business portfolios began in the late 1950s and evolved through the 1970s.

Portfolio management became a well-established planning tool in major companies around the world ${ }^{1}$. Companies originally used the tool to balance business units and prioritize resource allocation. Since that time, portfolio management processes have been adapted for use in other resource allocation decisions. In the 1980s and 1990s, companies extended the use of portfolio management into new product selection and Research \& Development resource allocation. Though the tools and uses have changed over time, the basic need remains the same. Companies must allocate resources to projects that balance risk, reward and alignment with corporate strategy, while remaining within their resource limits.

Investment Management provides a useful analogy for technology portfolio management. The client has an overall goal for his/her investment portfolio. The goal states the desired levels of stable income, liquidity, and long-term growth balanced against the tolerance for risk and the overall size of the portfolio. The fund manager must allocate resources to diverse financial instruments in the proper proportions to meet the client's needs. The investment manager allocates the resources of the portfolio to balance risk and reward in the short and long term to achieve the overall portfolio goals. Balancing a financial portfolio has become a straightforward exercise using a variety of well-established methods that rely largely on quantitative metrics. The investment manager has numerous standardized ratios, formulas and graphs readily available to aid in the decision process. 
Technology portfolio management has not reached the same level of standardization as investment portfolio management. Project metrics vary greatly from one company to another ${ }^{2}$. Some measures are quantitative, like estimated return on investment, while others are qualitative, like alignment with company strategy. Varieties of portfolio management tools have been developed to account for different types of metrics. Mathematical and scoring models are better suited to measure quantitative results. Graphic and charting formats provide a better measure of qualitative metrics. The mixture of qualitative and quantitative goals makes it difficult to define and to measure the "optimum" balance of a technology portfolio. Using multiple tools to balance the portfolio can lead to information overload for the portfolio managers ${ }^{3}$. Technology portfolio managers often develop the final portfolio balance through professional judgment or a scoring/weighting method.

\section{Portfolio Management in Practice}

Portfolio management has three goals to satisfy: maximize the value of the portfolio, provide balance, and support the strategy of the enterprise. The factors to balance may change from one organization to another. Some common factors to balance are risk and reward, market and product line, near term and long term, and project type. The process of managing the portfolio brings about the activities that are normally associated with portfolios: project selection and prioritization, resource allocation and project implementation. There have been numerous methods to carry out these tasks in pursuit of the goals and each has it strengths and weaknesses ${ }^{5}$. Robert Cooper $e t a l^{6}$ breaks technology portfolio tools into three categories: classical, mapping, and mathematical programming.

\section{Classical Portfolio Tools}

Classical portfolio tools include scoring and sorting models and checklists. These methods predominantly seek to maximize the value of the portfolio through either financial or nonfinancial measures. English China Clay International uses a method called Expected Commercial Value to maximize the commercial worth of the portfolio. The method links the expected financial cost and benefit of the project with a probability decision tree that accounts 
for the uncertainty of a project's technical and commercial success. The expected commercial value is derived through a formula that incorporates the costs and probabilities of each stage of development accompanied by a score for the project's strategic importance. The expected commercial value is used to rank order the list of potential projects in the portfolio. This method and others like it are often criticized for over reliance on financial data and a general failure to identify if the right mixture of projects is in the portfolio.

An example of a non-financial scoring model for portfolio management is from the U.S. Corporate Research \& Technology unit of Hoechst-A.G., a large chemical company\&. Projects are numerically rated against a number of well-defined criteria in each of five categories: probability of technical success, probability of commercial success, reward, business strategy fit, and strategic leverage. The scores for each category are summarized into a single rating to develop an overall Program Attractiveness Score. The computed attractiveness score is considered along with the mix of projects, the resources required and the resources available to prioritize the projects and make Go/Kill decisions during gate reviews. This method of portfolio decision making can be quite rigorous if the criteria within the scoring categories are well balanced. The method still lacks efficiency in allocation of resources and can suffer from false precision when comparing the attractiveness scores of two projects.

The checklist is a variation of the scoring model. The checklist has multiple criteria supporting multiple categories just like the scoring model, however, instead of assigning a score, the criteria is answered with a Yes/No based on a hurdle". A single "No" answer kills the project. This type of portfolio tool is time efficient with regard to project review meetings and is well suited for weeding out poor projects early. However, checklists do not provide differentiation within a portfolio to rank order projects and are ill suited for evaluating the balance within a portfolio.

\section{Mapping Portfolio Tools}

Mapping portfolio tools use graphical and charting techniques to portray the balance of the portfolio. Simple, two-axis diagrams easily display the trade off between two criteria at a time. 
Common two-axis diagrams display the trade-off between risk versus reward, probability of success versus value, or ease of implementation versus attractiveness. The measures may be a quantitative value like estimated Net Present Value or may be a qualitative assessment like low to high. A bubble diagram is a variant of the risk-reward diagram that uses a circle or ellipse to identify each project instead of a single point. The size, shape, color and shading of the circle may provide additional information about the project. For instance, the size of the circle may represent annual resources, the color: timing, and the shading: product line. A bubble diagram developed at $3 \mathrm{M}$ Company uses an ellipse to display the range of possible outcomes on the two axes of probability of success and NPV ${ }^{10}$. Mapping tools can successfully incorporate numerous portfolio balance criteria into a single diagram, but they do not result directly in a prioritized list of projects. The diagrams only provide a starting point for the discussion of prionity.

Another portfolio mapping tool relates research technologies to the potential products then to the final markets. Similar to a precedence network, it accounts for interdependencies between projects and relates them to their potential economic benefit. The product-technology roadmaps are graphed horizontally over a time scale. The projects and products are displayed as bubbles or bars that cover the time span for their period of development. Arrows link the $R \& D$ projects with each other and their dependent products ${ }^{11}$. This method provides a means to display the links between projects and the strategy of the company, though it does not address the balance of the portfolio or the maximizing of its financial return.

\section{Mathematical Programming}

The earliest portfolio management techniques treated the process as a mathematical model that optimized the commercial value of the portfolio within its resource constraints ${ }^{12,13,14}$. These models were supported by the management science community, though they often lacked credibility with portfolio managers in practice. The mathematical approach had inherent drawbacks. First, modeling techniques focused heavily on maximizing value, but paid little attention to providing balance or to aligning the portfolio with the strategic direction of the company. Second, the models relied on financial projections of each project's commercial 
value. This is often difficult to estimate when the projects or products may be years away from market introduction. The uncertainty in the financial projections limited the usefulness of the objective function. Relying principally on a single criterion that had a high degree of uncertainty made the method impractical and reduced its credibility ${ }^{15}$. However, in recent years, mathematical programming and project selection models have become more practical and realistic ${ }^{16}$.

\section{Portfolio Management at Boeing}

In 1997, The Boeing Company developed a gate review process in conjunction with a portfolio management process to support a new program. The program within Boeing Commercial Airplanes was responsible for developing the processes that would dramatically reduce the time and resources required to design, build, and introduce new airplane models. The gate review process and portfolio management tools employed were typical; however, the content of the portfolio itself was unique. Most technology portfolios relate to $R \& D$ research or potential new products. Boeing's portfolio was a set of recommended changes to the product development process itself. This created a portfolio of interdependent projects that would be implemented over a number of years.

Boeing employed a combination of classical and mapping tools to manage their portfolio. These tools are discussed in Chapter 2. Balancing the portfolio with their existing tools was both tedious and complex. The complexity of project interdependency over time required a new integrated decision support tool to assist in the portfolio balancing process.

This paper presents an approach to account for and quantify the interdependencies of technology projects and explains how it was integrated with their existing portfolio tools into a non-linear, integer Optimization Model at Boeing to balance a technology portfolio. The model selects if and when to start funding a project over a four year period. The effectiveness of each project in each year is influenced by whether or not the projects that it depends upon are also funded in that year. The funding choices influence the balance of identified risk, the support for designated categories of objectives, and the portfolio's cost and estimated financial 
return. Optimizing the model identifies the funding strategy that maximizes the potential return subject to the spending and portfolio balance constraints. Once the "optimum" strategy is found, the model is used to explore the impact of alternate portfolio strategies in real-time. When the strategy is altered in the model, the portfolio's performance is displayed in graphic formats similar to Boeing's existing portfolio management tools.

\section{Conclusion}

Portfolio management tools have been in existence for a number of years. Despite the number of portfolio tools available, it is difficult to identify a single tool that satisfies all three goals of portfolio management: maximize the value of the portfolio, provide balance, and support the strategy of the enterprise ${ }^{17}$. Mathematical and scoring models are better suited to measure quantitative results. Graphic and charting formats provide a better measure of qualitative metrics and relationships. The mixture of qualitative and quantitative goals makes it difficult to define and to measure the "optimum" balance of a technology portfolio. The additional complexity of project interdependencies further complicates the portfolio management process at Boeing. This paper presents an approach to quantify the interdependencies of technology projects and explains how it was integrated with their existing portfolio tools into a non-linear, integer optimization model at Boeing to balance a technology portfolio. 


\section{PORTFOLIO MANAGEMENT IN BOEING COMMERCIAL AIRPLANES}

\section{Introduction}

In 1997, The Boeing Company launched a program to define and develop the processes that would dramatically reduce the time and resources required to design, build, and introduce new airplane models. A cross-functional board was created to develop and administer a gate review process and to manage the program's potential process changes as a portfolio of projects. This chapter reviews the origin of the program and explains the portfolio management process that they developed.

\section{Airplane Creation Process Strategy}

In 1996, Airbus Industries, the European Airplane Consortium, announced that they were going to develop a "super-jumbo," the $\mathrm{A} 3 \mathrm{XX}^{18}$. The plane would be larger than the 747 , fly farther and have a lower operating cost per passenger for the airlines. With this new plane, they expected to take away the lucrative top end of the market that Boeing had dominated since the introduction of the 747 in 1970 . Airbus claimed that there was a potential market of over 1200 airplanes and that the plane would only cost a few billion dollars to develop. Boeing contended that there were less than 500 potential sales for a plane of this size and that the development cost for the plane would be much more than Airbus' estimate of $\$ 8$ Billion ${ }^{19}$. To secure their leadership in this market segment, Boeing immediately began working on an upgraded version of the 747 . The strategy was to position a new plane between the existing 747 and the proposed A3XX to steal away enough market share from Airbus so that the remaining sales would not justify their development $\operatorname{cost}^{2{ }^{2}}$. A moderate upgrade to the 747 could be accomplished for far less money and in far less time than an all-new design like the A3XX. 
A new product development program, the $747-\mathrm{X}$, was chartered to start defining the statement of work. The initial concept was a stretched version of the existing airframe with new avionics. As the program gained momentum and customer airlines were brought on board, the statement of work expanded. Soon the changes included a new wing design and numerous other improvements. After several months, the development program had accumulated manpower and was prepared to become a full-fledged development program. The last big hurdle was to take the business case to the President of Boeing Commercial before gaining final approval from The Board of Directors.

The 747-X program leaders assembled all of the final financial data for the presentation to the Office of the President. It was then that they realized that the program couldn't provide a positive Net Present Value at the required hurdle rate. They ran the numbers through several scenarios and the results were the same: the net present value of the airplane's sales revenue would never offset the cost and time required for its development. The team presented their findings to the Office of the President. The ramifications of their conclusions were staggering. Boeing could no longer afford to develop and to introduce large new airplanes. Because of that meeting, the President of Boeing Commercial Airplanes canceled the 747-X development program and chartered a new team ${ }^{21}$. The charter statement stated, "Initiate an intensive 'program' type effort to find a different way to approach new airplane development and production to be able to eventually build a new airplane." 22 The new team came to be known as the Airplane Creation Process Strategy Team (ACPS).

A core team of process experts from across the company was assembled. Meanwhile, the goal had been refined by the President to support the minimum business case requirements. The new target was to define processes to design and build a new airplane in half the time at half the cost. Achieving his goal would generate a positive net present value for a new airplane program. The team was directed to focus solely on non-recurring processes and costs of designing and developing a new airplane. The flow-time began at firm engineering configuration and ended with delivery to the first customer, including flight test and certification. A sub-team began collecting the data from the most recent new airplane programs to combine them and establish the baseline cost and flow-time profiles for 
comparison. The extensive model that resulted became the baseline for all business case justifications of proposed process changes.

The leader of ACPS was concerned that if they tried for a 50\% improvement in cost and flowtime, the tendency of the team would be to modify the existing processes. They decided to create a stretch target that would force everyone on the team to begin with a clean slate. They elected to change their target to approximate an order of magnitude improvement over the current baseline. The goal was revised to define the processes of a company that could design, build and deliver a new airplane for one billion dollars in 10 months. The goal became known as $1 / 10$ (One in Ten).

\section{ACPS Portfolio Management Process}

Teams began to develop proposals that would transform the airplane creation process. The implementation of ACPS was expected to occur over a number of stages. The stages, beginning with Stage A, would overlap slightly as the projects made a transition from the ACPS team that developed the idea to the functional organization that would implement and employ the process in the long term. Stages allowed large projects to be divided into pieces that are more manageable and allowed projects from different areas to progress at different paces. The early Stages of ACPS were roughly coordinated with the fiscal budgeting cycle.

One team developed the project selection process that would ensure that resources were allocated wisely and that the ACPS program would stay on target for the long-term goal. The team established a cross-functional Portfolio Management Board (PMB) to develop and administer the gated selection process. For each stage of ACPS implementation, the PMB would hold four gate reviews of the proposed projects (see Figure 1). At the end of each review, each project was given direction to go ahead as planned, to modify their plan as directed, to combine with another project or to kill the project. Projects that moved forward through each gate review were managed as a portfolio. The goal of the portfolio was to balance near and long term benefits, cost, risk, and support for ACPS's strategic objectives. 


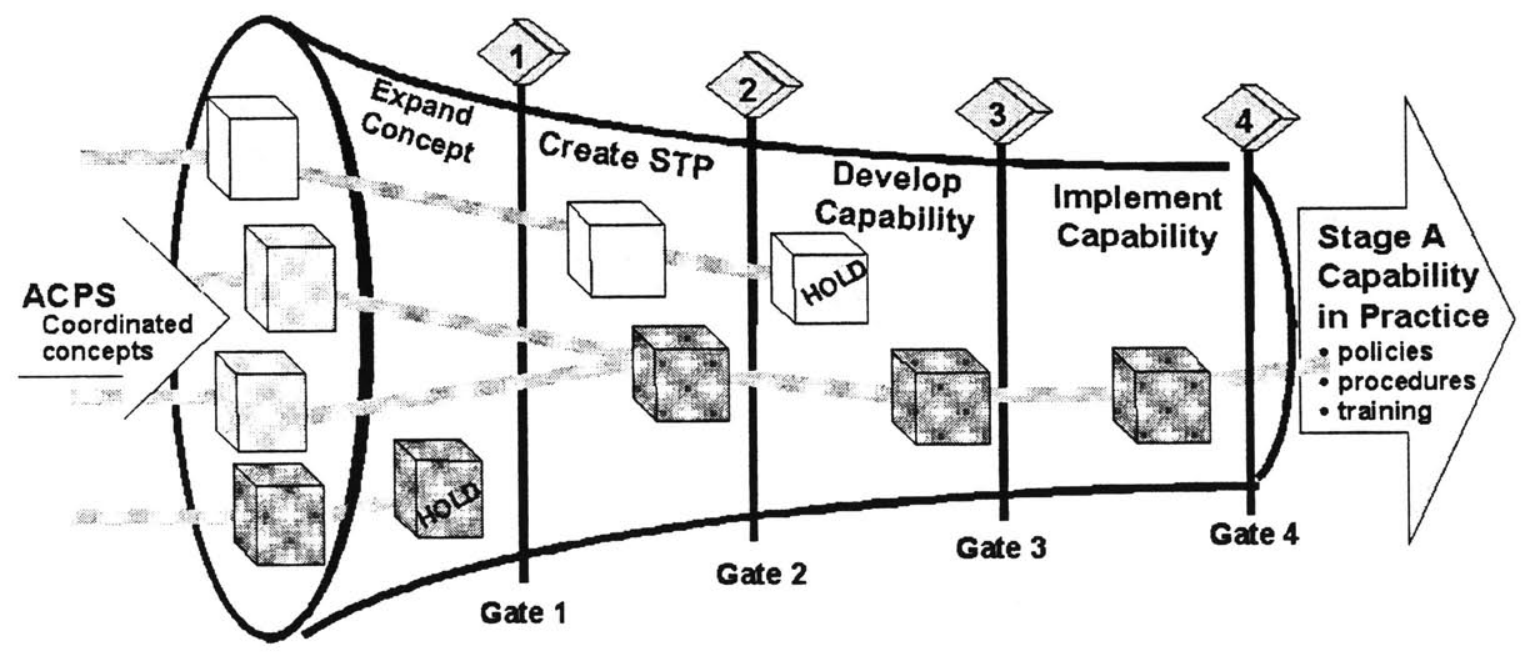

Figure 1 - ACPS Stage Gate Selection Funnel

The Portfolio Management Board received approximately eighty different project proposals for the first gate review of Stage A. The proposals were submitted in a common format called a Situation-Target-Proposal (STP). The STPs described the current process (situation), the near-term and $1 / 10$ vision for the process (target), and how to change or replace the process for Stage A (proposal). Accompanying the STP was a myriad of supporting data.

To balance the portfolio, the PMB used a variety of tools. The financial balance depended upon a standardized business case analysis for each STP. Risk was measured by estimating the STP's probability of success. Project interdependencies were discussed and charted graphically. A bubble diagram displayed the risk associated with the level of change proposed by the STP. Finally, the strategic balance was summarized by identifying which of the ACPS 
program's seven strategic objectives the STP most closely supported. STPs had to support at least one strategic objective or they were eliminated.

\section{Financial Summary}

The goal of the ACPS program was to save flow-time and non-recurring cost during airplane development programs. In order to measure program success, ACPS needed to establish a baseline development program as a reference. A group collected summaries of the nonrecurring financial data from the most recent development programs. The data were mapped into a large matrix that categorized the costs by functional group (engineering, tooling, QA, etc.) and by production assembly (e.g. outboard spar assemblies). Costs were further divided into labor and non-labor categories. Flow-time data was collected from each of the recent development programs and related to the timing of the financial expenses in each category. The result was a financial model that linked program cost with program flow-time. The model was consistent and accurate when validated against other program plans and historical data.

Situation-Target-Proposals were subjected to a common business case analysis based on the financial model. Each group developing an STP attended a seminar hosted by the financial model group. Together they identified the areas of cost and flow-time in the baseline program that would be affected by the STP. The groups then decided the level of potential impact that the STP would have on those areas. At the end of the seminar, the financial model produced a summary of the business case. The summary contained the projected implementation cost of the STP by year beginning in the current year, the projected program savings by year if the baseline program were launched two years hence, and the net present value of the STP (see Figure 2). 


\section{Sample STP Business Case Analysis Summary}

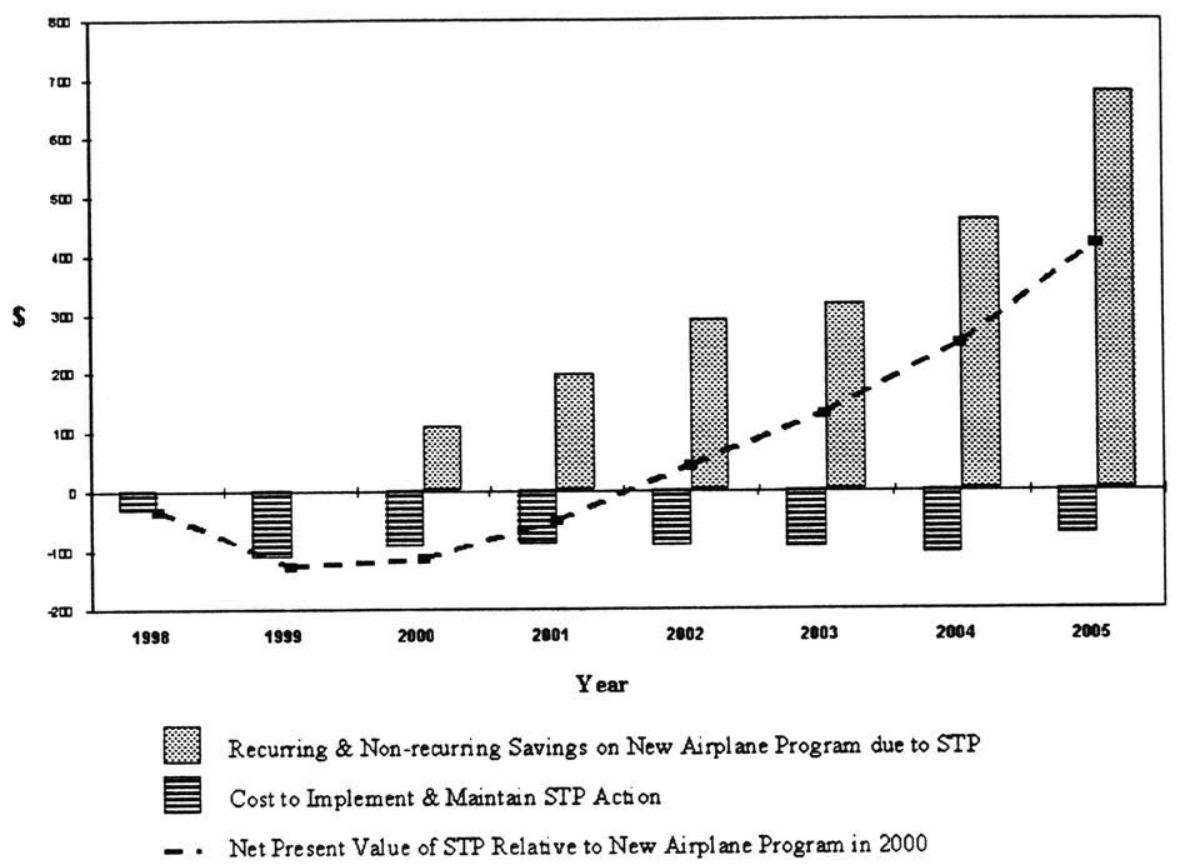

Figure 2 - Sample STP Financial Summary

\section{$\underline{\text { Probability of Success }}$}

The probability of success of each STP had to account for both the technical feasibility and the chances of successful implementation. The PMB borrowed a practice that was developed at General Electric called Quality $\times$ Acceptance $=$ Effectiveness. Quality is the technical feasibility of the proposal and its potential to correct the problem rated on a scale from one to ten. Acceptance is a value from one to ten that relates to the probability of the proposal being fully implemented based on the culture of the organization. The Effectiveness is the product of Quality and Acceptance. The PMB used Effectiveness as the percent probability of success for the STP. For example, an STP with a quality value of 8 and an acceptance value of 5 resulted in an overall probability of success of $40 \%$. 
The PMB used the probability of success value in three ways. First, the value itself helped as a criterion in the gate reviews. Second, if the probability of success of an STP was rated low, the PMB could better communicate to the submitting team whether the weakness was technically or culturally based. The probability of success was also multiplied by the projected revenue of the STP to weight financial return of the portfolio to arrive at an aggregate expected return.

\section{Project Interdependence}

The PMB knew that many of the projects were interdependent, especially those that supported a common ACPS strategic objective. They created a wall-sized dependency network between all Stage A STPs. Unfortunately, the network had so many links that they had difficulty interpreting the data. Furthermore, they did not have a means to quantitatively incorporate the information into the decision making process. They decided to account for the dependency using the qualitative assessment of the portfolio board members.

\section{Capability and Process Change}

As stated in the first chapter, it is common for portfolio managers to use risk-reward diagrams. The Portfolio Management Board developed a variation of this relative to the company's processes and capabilities, where the magnitude of changes in the process relate to risk and the resulting capability of the process relates to reward. For instance, it is more desirable to make an incremental process change to receive a dramatic increase in process capability than to make a big change in the process for only a small change in capability. Changes in process and capability are generally highly correlated. The Capability and Process Change Matrix captures the relationship and relative magnitude of these parameters for each project. The scale of change ranges from "None" to "New Core Process/Capability."

The projects were plotted in their general position on a matrix (see Figure 3). Projects in the lower left corner were dubbed "Planning STPs" because they were low risk and generally provided infrastructure for later stages of implementation. The next zone, titled "Incremental STPs", generally contained near term payoff projects with medium risk. These STPs typically 
modified an existing process in the company. The final region, "Platform STPs", were higher risk projects based on developing new processes and capabilities in the company. Each of the three zones was assigned a unique color to add visual clarity. Additional information was shown on the diagram to portray the status of the STP as of the most recent gate review. Red circles identified projects that either were on hold or were about to be canceled. Blue squares represented project proposals that were being revised or combined with other STPs. The black squares identified the STPs that were given the go ahead at the last gate review. The Portfolio Management Board wanted the portfolio to have a balance of process and capability change as well as a balance of risk.

\section{ACPS Capability / Process Matrix with Gate 2 STPs}

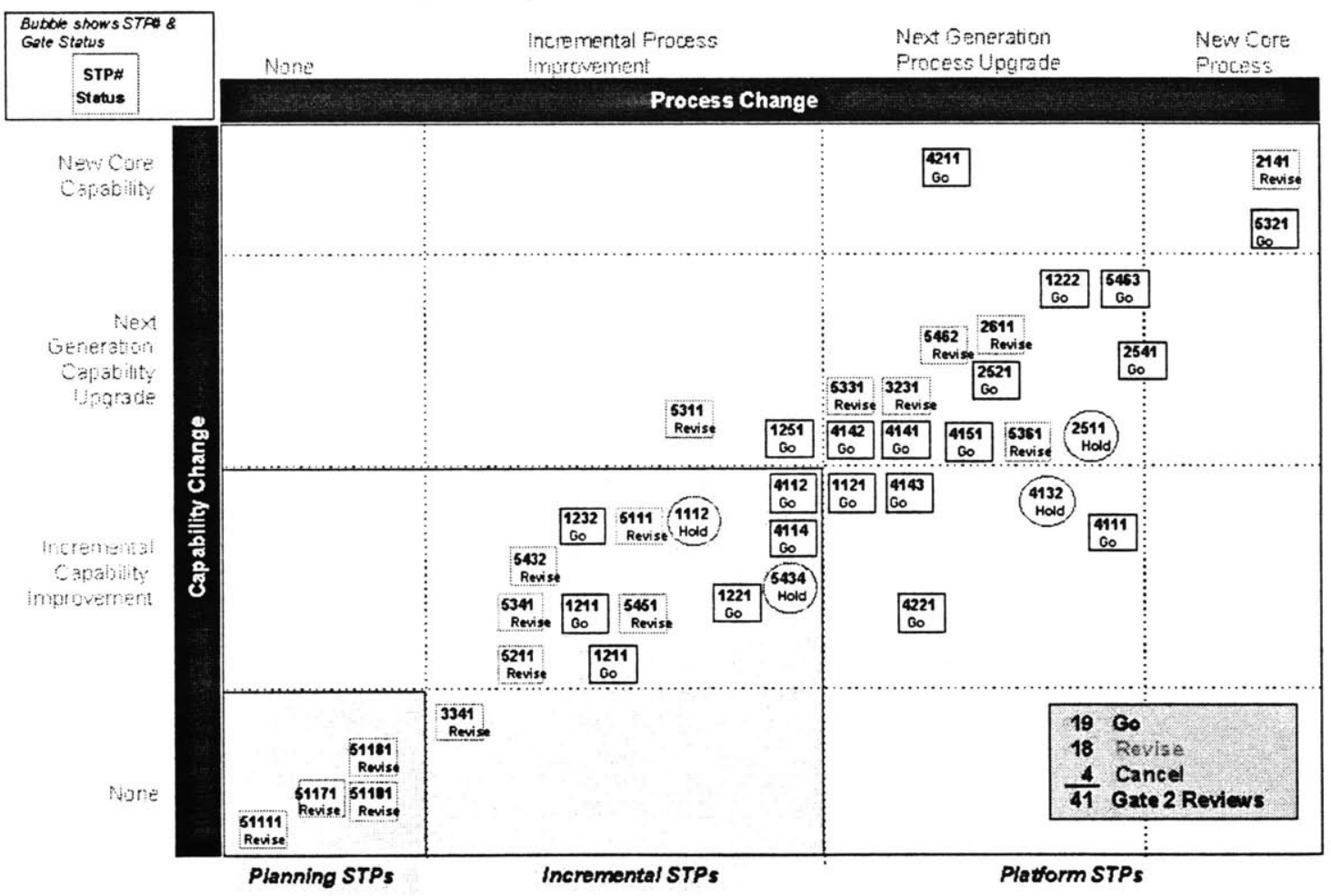

Figure 3 - Sample Capability \& Process Change Matrix ${ }^{23}$ 


\section{$\underline{\text { Strategic Objectives }}$}

The third method of viewing the balance of the portfolio was a chart identifying how the STPs aligned with the strategic objectives of ACPS. For example, one objective was to establish a common platform design center for all of Boeing Commercial Airplanes. The PMB aligned each project with the one objective it most strongly supported. Then they ranked the projects within each objective. The projects were arranged under the title of each objective from highest rank at the top to the lowest at the bottom (see Figure 4). The colors from the three zones of the Capability and Process Change Matrix were carried forward with each STP to provide a visual indication of risk.

\section{Sample Strategic Objectives Ranking}

\begin{tabular}{|c|c|c|c|c|c|c|c|c|c|c|c|c|c|}
\hline \multirow{2}{*}{\multicolumn{2}{|c|}{ 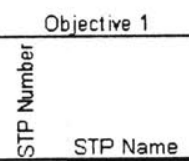 }} & \multicolumn{2}{|c|}{ Objective 2} & \multicolumn{2}{|c|}{ Objective 3} & \multicolumn{2}{|c|}{ Objective 4} & \multicolumn{2}{|c|}{ Objective 5} & \multicolumn{2}{|c|}{ Objective 6} & \multicolumn{2}{|c|}{ Objective 7} \\
\hline & &  & STP Name & 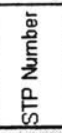 & STP Name & 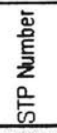 & STP Name & 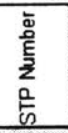 & STP Name & 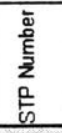 & STP Name & 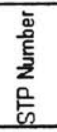 & STP Name \\
\hline 5451 & $\overline{\overline{z x x}}$ & 2521 & $x \mathbf{x x x}$ & 2711 & 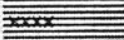 & 1232 & $\overline{\overline{z x x}}$ & 3341 & 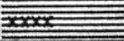 & 5461 & $\overline{\overline{u x x}}$ & 3231 & $x \times x x$ \\
\hline 5463 & $x x x x$ & 4142 & $x \times x x$ & $511 / 1$ & $x \times x$ & 1121 & $x x x x$ & 3361 & $x x x x$ & 5211 & 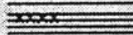 & 2611 & $x x x x$ \\
\hline 4141 & $\overline{\overline{z x x}}$ & 2511 & sus & 51101 & $x \times x$ & 1111 & $x \mathrm{xxx}$ & 3411 & $x x$ & 5482 & 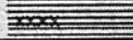 & 2541 & $x x x x$ \\
\hline 2141 & $x x x x$ & 2451 & $\overline{\overline{x x x}}$ & 5111 & 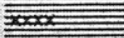 & 1112 &  & 2413 & $x x x$ & 5432 & 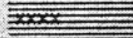 & 4131 & $x \times x x$ \\
\hline 5472 & $x \times x$ & 4211 & $x \times x x$ & 5321 & $x \mathrm{xxx}$ & 4133 & $x x x x$ & 3421 & $x \times$ & 1211 & 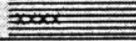 & 5311 & $x \times x x$ \\
\hline 5471 & $x x x \times$ x & & & 51111 & $x x$ & $\$ 114$ & 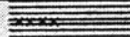 & 3431 & ox & 1251 & 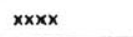 & 2411 & $x \times x x$ \\
\hline 51181 & $x x x x$ & & & 5341 & 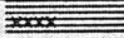 & 1222 & $x x x x$ & 3441 & 600 & 5434 &  & 5251 & 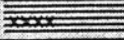 \\
\hline 3131 & $x \times x$ & & & 5361 & $x \mathrm{xxx}$ & 4151 & $x x x x$ & 3451 & $\mathbf{x x x x}$ & 5431 & $\overline{\overline{x a x}}$ & 5241 & $x x$ \\
\hline 2431 & $x x x x$ & & & 5331 & $x \mathrm{xxx}$ & 1221 & $\overline{\overline{x x x x}}$ & & & 4143 & $\overline{\overline{x x x x}}$ & & \\
\hline 4221 & $x x x x$ & & & 5351 & $x \mathrm{xxx}$ & 1331 & $x x x x$ & & & 4121 & $\overline{\overline{x x x}}$ & & \\
\hline 5462 & $x x x x$ & & & & & & & & & 4112 & 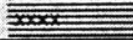 & & \\
\hline & & & & & & & & & & 4111 & $x \mathbf{x x x}$ & & \\
\hline
\end{tabular}

Planning STP Incremental STR

$\square$ Platform STP

Try. Canceled STP

Note: Project names have been removed from the chart due to the proprietary nature of the data.

Figure 4 - Sample Balance of the Strategic Objectives 


\section{Conclusion}

The final portfolio balance was generated by relying on the judgment of the board members to interpret the myriad of portfolio metrics. Discussing the merits of each project and how it related to the portfolio's balance was a painstaking and time consuming process. The PMB created four balanced portfolios based on different scenarios of the Capability and Process Change Matrix. The outcome was a ranked list of projects. The portfolio would consist of as many projects as they could afford in the first year of Stage A's implementation budget. The budget determined the cutoff point at about 30 projects. After the cutoff was made, the financial model was used to estimate the financial return of the whole portfolio taking into account the probability of success of each project's pay back. The model also estimated the portfolio's cost and flow-time savings based on the baseline business case.

The Stage A portfolio balancing process was considered a mixed success. It absorbed a large amount of data from the STPs and summarized it in just a few portfolio management tools. However, even at that level of complexity, the time and effort required by the Portfolio Management Board to balance the portfolio were very high. Consequently, when updated financial information became available in the latter part of Stage A, the portfolio was not rebalanced using the entire original process. Instead, they chose to "tweak" the original portfolio and re-estimate its cost and potential return. The major drawbacks of the process were related to its inability to quantify the impact of project interdependencies and account for the riskreward trade off at the individual project level. Stage B would bring even greater complexity. That latter gate reviews of Stage A would overlap with the early gate reviews of Stage B. The PMB did not have a means to balance the ACPS program level portfolio when STP interdependency crossed stages. The Portfolio Management Board needed to extend the capability of their tools to accomplish the task. 


\section{Chapter 3}

\section{OPTIMIZING INTERDEPENDENT PROJECTS OVER MULTIPLE TIME PERIODS}

\section{Research Overview}

The research for this thesis began after the portfolio management process had been established for the Airplane Creation Process Strategy program (ACPS). The Portfolio Management Board (PMB) balanced the portfolio using data predominantly from the first of four gate reviews for Stage A of the program. The portfolio of project proposals (STPs) was balanced using a variety of tools. Each tool provided information on a particular aspect of the portfolio's balance. The PMB relied on their cross-functional expertise in discussions about these tools to balance the overall portfolio. The ACPS portfolio management process was thorough, but tedious. The process was unable to quantify the impact of project interdependencies and account for the risk-reward trade off at the individual project level. The next stage of the program would bring even greater complexity. The latter gate reviews of Stage A were expected to overlap the early gate reviews of Stage B. The existing tools used by the PMB were not well equipped to account for project interdependencies across multiple stages of the program's implementation.

The research for the thesis culminated in two new portfolio tools. First, the Dependency Matrix was developed to document and to quantify the interdependencies between project proposals. The matrix is scaleable and flexible so that the portfolio can be evaluated either within a single stage or across all active stages of the ACPS program. The goal of the matrix is to quantify the aggregate impact of project interdependencies in a format that supports the PMB's gate review process so that STPs can be added, canceled, or combined.

The second tool is a spreadsheet-based Optimization Model that integrates the Portfolio Management Board's existing tools into a non-linear, integer program. The model 
incorporates data from the Dependency Matrix to relate project interdependence with the estimated financial performance of the portfolio. The model identifies the funding strategy that maximizes the estimated financial return of the portfolio subject to portfolio balance and budget constraints. Once the "optimum" strategy is found, the model is used to explore the impact of alternate portfolio strategies in real-time. When the strategy is altered in the model, the portfolio's performance is displayed in graphic formats similar to Boeing's Stage A portfolio management tools.

The goals for the Optimization Model are:

- Utilize existing data

- Incorporate the effect of the Dependency Matrix

- Portray the performance of the portfolio in formats similar to the existing PMB tools

- Provide flexibility to evaluate alternatives and test assumptions

\section{The Dependency Matrix}

The Dependency Matrix is a square matrix of size $n_{p} \mathrm{x} n_{p}$, where $n_{p}$ is the number of projects. Each project represents one column and one row ordered identically, similar to a Design Structure Matrix ${ }^{24}$. Each element in the matrix, $d_{i}$ varies from zero to one. The value of $d_{i j}$ represents the level of dependency that project $i\left(1,2, \ldots, n_{p}\right)$ has on project $j\left(1,2, \ldots, n_{p}\right)$. A value of zero implies that the project $i$ is entirely independent of project $j$ for its financial success. A value of one implies that project $i$ is entirely dependent on project $j$ for its financial success. $A d_{i j}$ value of one also indicates that the Portfolio Management Board should consider combining the two projects at the next gate review. Where $i$ equals $j$, the $d_{i j}$ elements are zero.

The quantity and magnitude of the values in the matrix provide a relative sense of the dependencies between projects. Comparing projects by row (i) provides a relative sense of how dependent a project is on other projects. Comparing by column (j) indicates how strongly a project influences the outcome of other projects. 


\section{Applying the Dependency Marrix}

Next, the dependency values $d_{i j}$ are adjusted to provide a relative measure of impact on the revenue for each project $i$. To calculate this, we need an estimate of how much of each project's revenue is attributable to itself and how much is attributable to its interdependencies. A new input variable is introduced called the Minimum Benefit Level $\left(M_{i}\right)$. It defines the decimal percent of the revenue expected if project $i$ were funded without the benefit of funding the projects $j$ that it depends upon. For example, if $M_{i}$ were 0.85 and STP $i$ were the only project funded in the portfolio, then we would expect $85 \%$ of the revenue estimated from its business case analysis. The remaining $15 \%$ of the expected revenue depend upon other STPs that were not funded. We can distribute the remaining benefit of project $i\left(1-M_{i}\right)$ across the projects $j$ that it depends upon. The distribution is based on the relative weight of the dependency values $d_{i j}$ for each project $i$. The value of $W_{i j}$ is the weighted dependency of project $i$ on project $j$.

$$
W_{i j}=\left(1-M_{i}\right) *\left(\frac{d_{i j}}{\sum_{\alpha=1}^{n_{p}} d_{i \alpha}}\right)
$$

Therefore, the sum of the minimum benefit level $M_{i}$ and the weighted dependencies for every project $i$ is equal to one.

$$
1=\sum_{j=1}^{n_{p}} W_{i j}+M_{i}
$$

To determine the net effect of the dependencies for project $i$ we need information on which projects are concurrently funded. The binary decision variable $X_{j}$ identifies which projects will be funded, one if project $j$ is funded and zero otherwise. Thus, the net effect of the dependency $\left(D_{j}\right)$ is the sum across all projects $j$ of the product of the project decision variable $X_{j}$ and the weighted dependencies $W_{j}$.

$$
D_{i}=\sum_{j=1}^{n_{p}} X_{j} W_{i j}
$$


The following example illustrates the process. Project $i$ is dependent on two other projects $j$, both with dependency values $\left(d_{j}\right)$ of 0.2 . Project $i$ 's minimum benefit level $\left(\mathrm{M}_{i}\right)$ is estimated at 0.8 . The business case analysis projected revenue for project $i$ at $\$ 100,000$. If project $i$ is funded, but the two projects $j$ are not, then the expected revenue from project $i$ is $\$ 80,000$. The remaining 20\% (1-M $\left.M_{i}\right)$ of the potential benefit of project $i$ is distributed between the two projects $j$ based on the relative weight of their dependency values $\left(d_{i j}\right)$; in this case 0.10 or $\$ 10,000$ each. Thus, if project $i$ and one of the projects $j$ are funded, the expected revenue from project $i$ would be $\$ 90,000$.

\section{Sample Dependency Matrix}

The following is an example of a Dependency Matrix with its values $d_{i j}$. Note that no projects are dependent upon Project 1 and that the diagonal values are zero where $i=j$.

\begin{tabular}{|c|c|c|c|c|c|}
\hline & \multicolumn{5}{|c|}{ Projects $j$} \\
\hline \multirow{5}{*}{$\frac{0}{0}$} & & Project 1 & Project 2 & Project 3 & Project 4 \\
\hline & Project 1 & 0 & 0 & 0 & 0 \\
\hline & Project 2 & 0 & $\overline{0}$ & 0.3 & 0.1 \\
\hline & $\overline{\text { Project } 3}$ & 0 & $\overline{0}$ & $\overline{0}$ & 0.1 \\
\hline & $\overline{\text { Project } 4}$ & $\overline{0}$ & 0.2 & 0.1 & $\overline{0}$ \\
\hline
\end{tabular}

Next, sum the values of $d_{i j}$ for every project $i$.

\begin{tabular}{|c|c|c|c|c|c|c|}
\hline & \multicolumn{5}{|c|}{ Projects $j$} & \\
\hline \multirow{5}{*}{$\frac{n}{\tilde{u}}$} & & Project 1 & Project 2 & Project 3 & Project 4 & Sum \\
\hline & Project 1 & 0 & $\overline{0}$ & 0 & 0 & $\overline{0}$ \\
\hline & Project 2 & 0 & 0 & 0.3 & 0.1 & 0.4 \\
\hline & $\begin{array}{l}\text { Project } 3 \\
\end{array}$ & $\overline{0}$ & 0 & $\overline{0}$ & 0.1 & 0.1 \\
\hline & \begin{tabular}{|l|} 
Project 4 \\
\end{tabular} & $\overline{0}$ & 0.2 & 0.1 & $\overline{0}$ & 0.3 \\
\hline
\end{tabular}

Normalize the values of $d_{i j}$ for each project $i$ as shown.

\begin{tabular}{|c|c|c|c|c|c|c|}
\hline & \multicolumn{7}{|c|}{ Projects $j$} & \\
\hline \multirow{2}{*}{} & & Project 1 & Project 2 & Project 3 & Project 4 & Sum \\
\cline { 2 - 7 } & Project 1 & 0 & 0 & 0 & 0 & 0 \\
\cline { 2 - 7 } & Project 2 & 0 & 0 & 0.75 & 0.25 & 1 \\
\cline { 2 - 7 } & Project 3 & 0 & 0 & 0 & 1 & 1 \\
\cline { 2 - 7 } & Project 4 & 0 & 0.67 & 0.33 & 0 & 1 \\
\cline { 2 - 7 } & & &
\end{tabular}


The minimum benefit level for each project is introduced. Note that if the project is not dependent upon any other project, then by definition, the minimum benefit level must be one. In the example below, if Project 2 were the only one funded, the project would expect $80 \%$ of the financial benefit claimed in the project's business case analysis.

\begin{tabular}{|c|c|c|c|c|c|c|c|}
\hline & \multicolumn{5}{|c|}{ Projects $j$} & \multirow[b]{2}{*}{ Sum } & \multirow[b]{2}{*}{$M i$} \\
\hline \multirow{5}{*}{$\begin{array}{l}\frac{n}{0} \\
\frac{0}{2} \\
2\end{array}$} & & Project 1 & Project 2 & Project 3 & \begin{tabular}{|l|} 
Project 4 \\
\end{tabular} & & \\
\hline & Project 1 & 0 & 0 & 0 & 0 & 0 & 1 \\
\hline & $\overline{\text { Project } 2}$ & 0 & 0 & 0.75 & 0.25 & 1 & 0.8 \\
\hline & $\overline{\text { Project } 3}$ & 0 & $\overline{0}$ & $\overline{0}$ & 1.00 & 1 & 0.9 \\
\hline & Project 4 & $\overline{0}$ & 0.67 & $\overline{0.33}$ & $\overline{0}$ & 1 & 0.6 \\
\hline
\end{tabular}

Next multiply the normalized dependency values by the benefit level attributable to the dependent projects $\left(1-M_{i}\right)$. In the case of Project 4, this number would be 0.4 (1-0.6). The resulting weighted dependency factors $W_{j}$ are shown below. Note that the sum of the weighted dependencies $W_{i j}$ and the minimum benefit level $M_{i}$ are now equal to one for each project $i$.

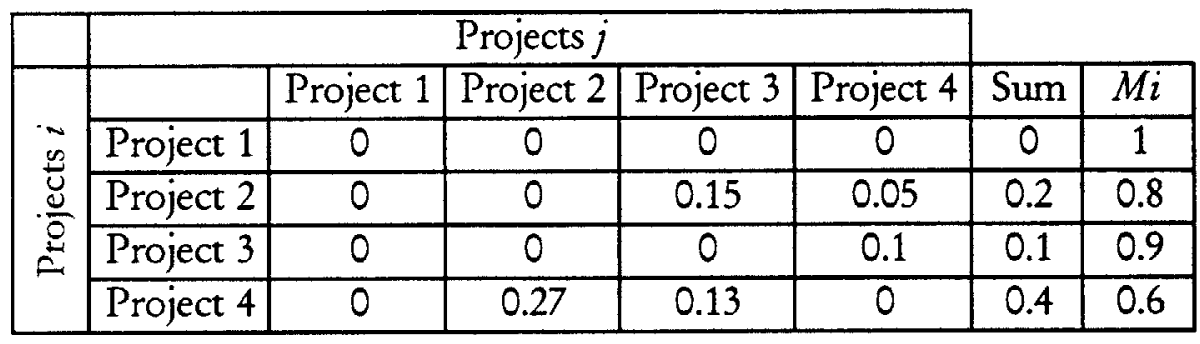

For a given year, if it is known which projects are funded and which are not $\left(X_{j}\right)$, then the Minimum Benefit Level $\left(M_{i}\right)$ and the Weighted Dependencies $\left(W_{i j}\right)$ are used to calculate the fraction of expected revenue for any funded project. Based on the data above, if Projects 2 and 4 are the only projects funded, then they would be expected to achieve $85 \%$ and $87 \%$ of their revenue potential respectively. Since no other projects are dependent upon Project 1 , its absence does not adversely effect the portfolio. However, by leaving Project 3 out of the portfolio, Projects 2 and 4 lose $15 \%$ and $13 \%$ of their potential revenue respectively based on the weighted dependencies $W_{i}$. 


\begin{tabular}{|c|c|c|c|c|c|c|c|c|c|}
\hline & \multicolumn{5}{|c|}{ Projects $j$} & & & & \multirow{2}{*}{$\begin{array}{c}\text { Expected } \\
\text { Benefit }\end{array}$} \\
\hline \multirow{5}{*}{ 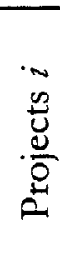 } & & Project 1 & Project 2 & Project 3 & Project 4 & Sum & $M i$ & $\overline{X j}$ & \\
\hline & Project 1 & 0 & 0 & 0 & 0 & $\overline{0}$ & 1 & 0 & 0 \\
\hline & Project 2 & 0 & 0 & 0 & 0.05 & 0.05 & 0.8 & 1 & 0.85 \\
\hline & Project 3 & 0 & 0 & 0 & 0 & 0 & 0.9 & 0 & 0 \\
\hline & Project 4 & 0 & 0.27 & 0 & 0 & 0.27 & 0.6 & 1 & 0.87 \\
\hline
\end{tabular}

As the portfolio management process adds, cancels and combines projects, the Dependency Matrix is adjusted accordingly. If a new project is developed, it is added to the Dependency Matrix as a new column and row. The new elements of $d_{i j}$ are added and new values of $W_{i j}$ are calculated. If a project is canceled, the row and column of that project are removed from the matrix and the weighted values of the remaining projects are recalculated. When projects are combined, the combined project is added just like a new project and the old separate projects are removed from the matrix. The old elements of $d_{i j}$ may be used to develop the new dependency values. By maintaining the matrix in the original format of the $d_{i j}$ elements, it is easily adapted as the portfolio changes over time.

Note that the dependency values in the matrix and the minimum benefit levels do not have to be precise numbers. There is no value in debating whether a $d_{i j}$ element should be 0.95 or 0.98. Even if the matrix elements are assigned standard values for zero, low, and high dependency (e.g. $0,0.25$, and 0.75 respectively), the matrix can be used to compare the effects of dependency on different combinations of projects in a portfolio. The accuracy and precision of the values should however be consistently applied to the entire matrix.

\section{Optimizing the Portfolio}

The Optimization Model is a spreadsheet-based non-linear integer program. It solves for the optimum group of projects to start in each year to maximize a portfolio's net present value subject to budgetary and portfolio balance constraints. The model utilizes the Dependency Matrix to estimate each project's revenue based on which other projects in the portfolio are funded. Once the optimal solution is found, the performance of the portfolio is displayed via pre-constructed graphs and charts that relate to the original Portfolio Management Board 
metrics. The "optimal" solution is intended as a starting point for the PMB to explore and evaluate alternative portfolio mixes. Changing the content and timing of the portfolio mix in the spreadsheet immediately updates the performance metrics.

\section{$\underline{\text { Decision Variables }}$}

The model's decision variable $\left(X_{i k}\right)$ is binary for each project $i\left(1,2, \ldots, n_{p}\right)$ in each calendar year $k\left(1,2, \ldots, n_{k}\right)$. A value of one indicates that project $i$ will start receiving funds in calendar year $k$; it is zero otherwise. A project can only be launched one time and once it has started receiving funds, it remains funded through the remaining years in the model.

\section{$\underline{\text { Input Variables }}$}

For each project $i$, the model requires data on its cost, revenue, probability of success, strategic objective, capability change level, process change level, minimum benefit level, and weighted dependencies. Each category of data with the exception of the minimum benefit level and weighted dependencies was developed for each project during the Stage A gate reviews of the ACPS program (see Chapter 2 - ACPS Portfolio Management Process). The minimum benefit level $\left(M_{i}\right)$ and weighted dependencies $\left(W_{j}\right)$ were established for each project in the Dependency Matrix.

The financial model used on the ACPS program provides a summary cost for each project by year. The value in each year represents the total cost, which includes capital expenditures, cost of implementation and sustaining costs. On ACPS, it is assumed that the cost in each year $t(0$, $1, \ldots, n$ ) of the project will not change no matter which calendar year $k$ it is launched. For instance, assume the project cost is projected to be 15 in the initial year of funding, 10 in the second year of funding and 4 in the third. If the project were launched in calendar year 1999, the cost incurred would be 15 in 1999, 10 in 2000 and 4 in 2001. However, if the project were initially launched in the year 2000, then the cost incurred in 2000, 2001 and 2002 would be 15, 10 and 4 respectively. The cost $C_{k t}$ is provided in a matrix format where each element 
represents the incremental cost of project $i$ in calendar year $t$ if the project starts in calendar year $k$.

The financial model also provides a summary of projected revenue for each project by year. The projects on the ACPS program are focused on saving non-recurring cost and flow-time on airplane development programs so the revenue generated by a project is dependent upon which year the airplane program is initiated. Generally, ACPS projects require one or two years of implementation before they are able to achieve their full revenue potential on an airplane development program. For example, if a project is initially funded in the same year that a new airplane development program is launched (where $t=0$ ) then the revenue potential is low. If an airplane program is launched a couple of years after the project's initial funding (where $t>$ $0)$, then the projected revenue is higher. The value in each element of the revenue matrix $R_{i k t}$ represents the total projected savings from project $i$ in calendar year $t$ if the new airplane program was launched in calendar year $k$.

The Portfolio Management Board rated each project on its probability of success, strategic alignment and risk. Each project was evaluated on its technical feasibility and its chances of successful implementation to arrive at a single value for probability of success. The probability of success of project $i\left(P_{i}\right)$ is a value between zero and one. The PMB also aligned each project with the strategic objective it most strongly supported (see Figure 4). The strategic objective $N_{z n}$ is a binary variable which is one if project $i$ supports objective $m\left(1,2, \ldots, n_{m}\right)$ and zero otherwise. In the model, a project can only support one strategic objective, although in reality it might support several objectives.

As a relative measure of risk in the portfolio, the PMB rated each project on its impact on the capabilities and the processes of the company (see Figure 3). The measures of capability and process change for each project are not assigned variables here because they are not a constraint or decision variable in the model. They are included solely to provide the graphical output for the Portfolio Management Board's metric of risk (see Model Output later in this chapter). 
The minimum benefit level $\left(M_{i}\right)$ and weighted dependencies $\left(W_{i j}\right)$ were established for each project in the Dependency Matrix. The minimum benefit level $\left(M_{i}\right)$ defines the decimal percent of the revenue expected if project $i$ were funded without the benefit of also funding the projects $j$ that it depends upon. The value of $W_{j}$ is the weighted dependency of project $i$ on project $j$ (see Equations 1 and 2).

Next, the net effect of the Dependency Matrix $D_{i k}$ is calculated for all projects $i$ in calendar year $k$. To do this we need an intermediate binary variable $\left(Y_{i k}\right)$ that is one if project $i$ is initially funded in year $k$ or any year prior to year $k$ and is zero otherwise. As stated earlier, once a project is started, it remains funded. The variable $Y_{i k}$ simply identifies if project $i$ is currently receiving funds in calendar year $k$.

$$
\begin{gathered}
Y_{i k}=\sum_{\beta=1}^{k} X_{i \beta} \\
D_{i k}=\sum_{j=1}^{n_{p}} W_{i j} Y_{j k}
\end{gathered}
$$

\section{Constraints}

There are three user-defined constraints in the model: budget, quantity of projects in the portfolio, and quantity of projects supporting each strategic objective. The budget $B_{t}$ represents the maximum amount of money available to spend on the portfolio of projects $i$ for each calendar year $t$. The cost in any given year cannot exceed the budget available.

$$
\sum_{k=1}^{n_{k}} \sum_{i=1}^{n_{p}} C_{i k t} X_{i k}-B_{t} \leq 0
$$

The second constraint is the maximum number of projects $(Q)$ the model is allowed to fund in the portfolio. This constraint provides flexibility to use the model as a tool to evaluate alternate portfolios. Using the model to evaluate the portfolio options is discussed in chapter 4. 


$$
\sum_{i=1}^{n_{p}} \sum_{k=1}^{n_{k}} X_{i k}-Q \leq 0
$$

The last user-defined constraint involves the number of projects that must support each of the strategic objectives $\left(M_{m}\right)$ of the program. The Portfolio Management Board decides which objectives to emphasize with the portfolio by identifying a minimum quantity of projects to support each objective.

$$
\begin{aligned}
& \sum_{i=1}^{n_{p}} \sum_{k=1}^{n_{k}} N_{i m} X_{i k}-M_{m} \geq 0 \\
& \text { Where } N_{i m}=1 \text { if project } i \text { supports objective } m \text { and equals } 0 \text {, otherwise. }
\end{aligned}
$$

The remaining constraint defines the limits on the decision variable. For the decision variable $X_{i k}$, each project can only be launched one time.

$$
\sum_{k=1}^{n_{k}} X_{i k} \leq 1
$$

\section{Model Objective Function}

The objective of the model is to find the combinatorial optimum set of projects to start funding in each calendar year to maximize the net present value of the entire portfolio subject to the budget, project quantity, and strategic alignment constraints. The revenue contributed by each project is influenced by its probability of success $P_{i}$ and the effects of the Dependency Matrix $M_{i}$ and $D_{i k}$. In the equation below, the net present value discount factor for each calendar year $t$ at the designated hurdle rate is represented by $F_{t}$.

$\operatorname{Max} \sum_{i=1}^{n_{p}} \sum_{k=1}^{n_{k}} \sum_{t=0}^{n_{t}} X_{i k} R_{i k t} F_{t} P_{i}\left(D_{i k}+M_{i}\right)-\sum_{i=1}^{n_{p}} \sum_{k=1}^{n_{k}} \sum_{t=0}^{n_{t}} X_{i k} C_{i k t} F_{t}$

Maximize discounted revenue - discounted cost

A small change in the objective function allows the model to maximize the NPV for a specified calendar year $k$ instead of across all years $k$. 


\section{$\underline{\text { Model Output }}$}

The performance of the portfolio is displayed via pre-constructed graphs and charts in the model's spreadsheet that relate to the original Portfolio Management Board metrics. Changing the content and timing of the portfolio $\operatorname{mix}\left(X_{i k}\right)$ in the spreadsheet either manually or with the solver immediately updates the performance metrics.

There are three graphic metrics provided by the model. The Capability \& Process Change Balance (see Figure 5) counts the number of funded projects in each category of process and capability change and portrays them as a percent of the whole. This chart is a modified version of the original Capability and Process Change Matrix (see Figure 3). The Capability and Process change metric provides the Portfolio Management Board with the relative balance of risk and reward in the portfolio.

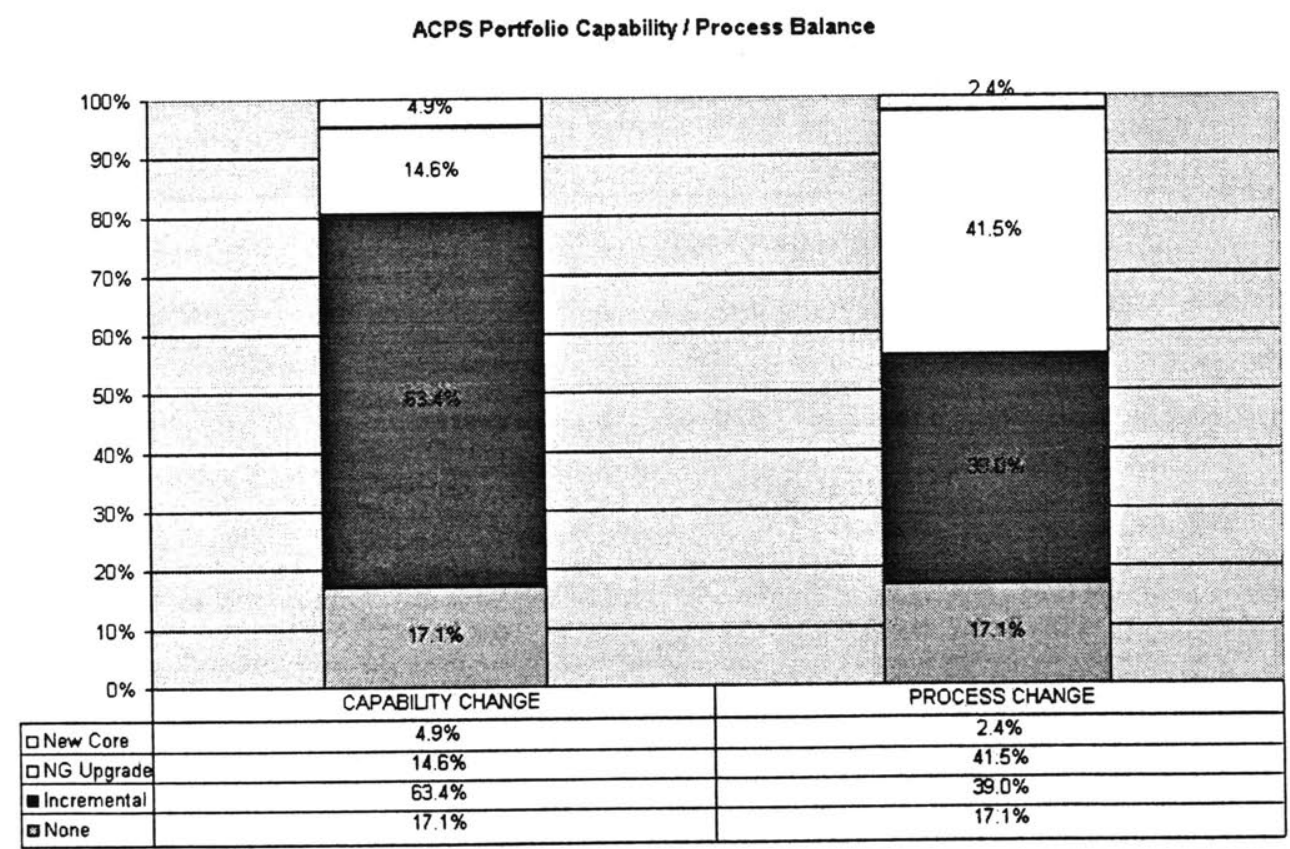

Figure 5 - The Capability and Process Change Balance

The second graph displays the quantity of projects in the portfolio supporting each strategic objective (see Figure 6). The constraint $M_{m}$ specifies the minimum quantity of projects 
required to support each objective. The graph reports the actual number based on the portfolio defined by $X_{i k}$. This graph is a summary of the PMB's Strategic Objective chart (see Figure 4).

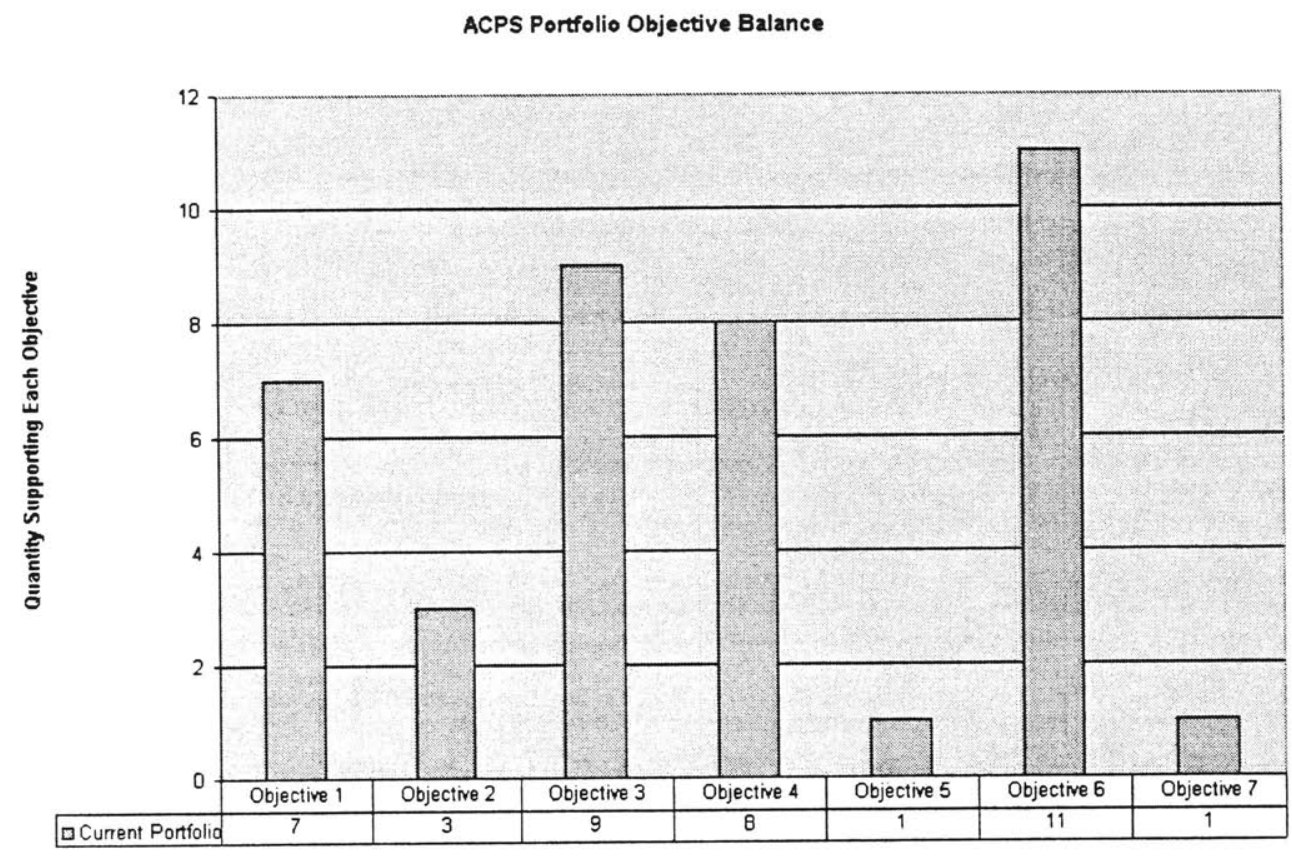

Figure 6 - Balance of Support for Seven Objectives

The financial summary (see Figure 7) portrays the cost, benefit and net present value of the funded projects over four calendar years of the model. The revenue shown is the sum of the product of each project's revenue $\left(R_{i k}\right)$, probability of success $\left(P_{i}\right)$, and its Dependency Matrix effect $\left(M_{i}+D_{i j}\right)$. The NPV uses the sum of the costs beginning from year one, but only the revenue in the year of interest (e.g. NPV in 2000 considers cost from ' 98 , ' 99 \& ' 00 , but benefit in ' 00 only). The ACPS data is constructed this way due to the pay back occurring primarily on a non-recurring basis in the year following the launch of a new airplane development program. As stated earlier, the value in each element of the revenue matrix $R_{i k}$ represents the total projected savings from project $i$ in calendar year $t$ if the new airplane program was launched in calendar year $k$. This helps the PMB to evaluate the implementation time between the initial funding of a portfolio and the launch of a new airplane program. 




Figure 7 - Sample Summary Financial Performance of the Portfolio

\section{Summary}

The Dependency Matrix is a simple format that allows the Portfolio Management Board to document the perceived effects of each project on all other projects. The format is scaleable and flexible to allow projects to be added, canceled or combined over the life of the ACPS program. The Optimization Model utilizes existing data, incorporates the aggregate effect of the Dependency Matrix, and integrates the existing portfolio management tools on the ACPS program. Using the optimal funding strategy as a starting point, the model's spreadsheet format provides flexibility to evaluate performance of alternative solutions. The performance of the portfolio is summarized in graphical formats similar to the PMB's existing portfolio management tools to simplify interpretation. 


\section{Chapter 4}

\section{APPLYING THE DEPENDENCY MATRIX AND THE OPTTMIZATION MODEL}

\section{Introduction}

The Dependency Matrix and the Optimization Model were created to enhance the Airplane Creation Process Strategy (ACPS) program's portfolio management process. The Dependency Matrix provides a method of documenting and quantifying the interdependencies between projects in a format that is scaleable and flexible. The Optimization Model incorporates the effect of the Dependency Matrix with the program's existing portfolio tools to create a model for evaluating the balance of a portfolio. The following chapter discusses the results of implementing the new portfolio management tools on the ACPS program.

\section{Solving and Applying the Optimization Model}

The Optimization Model was developed in Microsoft Excel and solved as a non-linear, integer optimization program using Frontline Systems' Premium Solver Plus for Excel. The

Dependency Matrix and the Optimization Model were developed just after the Stage A gate decisions were finalized and before data was available for the Stage B proposals. Therefore, the model was tested and validated using Stage $A$ data. The solver was not able to solve to optimality the problem with the integer restriction. However, when the integer constraint on the decision variable was revised to $0 \leq X_{i k} \leq 1$, the model quickly converged to a solution. Typically, only one or two out of the sixty projects in the solution resulted in fractional values when maximizing the financial benefit in different years. These fractional values were always biased heavily toward a single solution (e.g. 0.7 or more assigned to a single year $k$ ). This became the optimal solution for comparison with binary-constrained solutions and the solution generated earlier in Stage A by the Portfolio Management Board (PMB).

The financial output of the Optimization Model was validated against the ACPS financial model by comparing numerous identical portfolios with each tool. Next, the optimal solution 
for Stage A was compared with the original solution developed by the PMB. This comparison produced a few notable differences. First, the total revenue of the two portfolios was very similar, however the cost of the optimized portfolio was roughly $15 \%$ lower. This generated a higher net present value for the optimized portfolio. Second, the number of projects $(Q)$ in the two portfolios was very close. Third, approximately $40 \%$ of the projects were common to both portfolios.

The NPV-based objective function seemed to weigh costs more heavily than the PMB's original process. To test if this were true, the objective function was altered to maximize total revenue instead of NPV and the model was re-solved. Surprisingly, when revenue was maximized, the commonality of the projects in the two portfolios diverged even farther, but the total revenue remained about the same, albeit higher in the optimal. After some examination of the data, it became apparent that many of the projects had projected revenues of the same magnitude. Thus, there were numerous potential solutions to achieve nearly identical total portfolio revenues.

De-coupling the Dependency Matrix from the rest of the model creates a linear version that provides a means to examine the effects of project dependency. In the case of Stage A data, less than $5 \%$ of the elements $\left(d_{i}\right)$ in the Dependency Matrix were populated with values greater than zero. The mean value of the elements was roughly 0.3. The Dependency Matrix therefore had a weaker effect on the Stage A solutions than anticipated. The most noticeable effect of the Dependency Matrix was that it formed groups of interdependent projects. These project groups tended to stay together either in or out of the portfolio, especially when many optimization constraints were binding.

\section{Observed Benefits}

The intent of the Optimization Model is to provide a tool for the Portfolio Management Board to easily evaluate portfolio alternatives. Consequently, the mathematically optimum portfolio funding strategy found by the solver is intended to be a starting point for evaluation not the final solution. The PMB was more concerned with a model that was flexible, easy to 
manipulate and easy to interpret than it was with the speed or accuracy of the solver. The model also provided consistent results that were not available from the original PMB process.

The model's spreadsheet architecture made it simple to reconfigure to answer a variety of questions. The same basic model could be used to answer questions like, "If we could fund one more project this year, which one best supports the existing portfolio." To accomplish this task, the decision variables $\left(X_{i k}\right)$ for the existing portfolio are fixed by additional constraints. The project quantity constraint $(Q)$ is set to a value of one greater than the number in the current portfolio. In this way, the data from the existing portfolio is considered when evaluating additional projects. Through similar manipulation of the constraints, the model could answer other incremental questions like, "If we had X more dollars to spend this year, how much would it increase the NPV of the portfolio?"

The architecture of the model combined with use of the original portfolio metric data made it easier to re-evaluate the entire portfolio when project metrics were updated. For instance, new financial projections were available on many projects just before a scheduled stage gate review. The original process used by the PMB relied heavily on evaluating one project at a time. Although this process was thorough, it was time consuming and favored making small, incremental changes to the portfolio. With the Optimization Model, all of the new data could be imported into the model and the entire portfolio could be re-evaluated simultaneously. Furthermore, the model produced consistent results that were not attainable with the original portfolio balancing process.

Finally, the model allows the Portfolio Management Board to focus on balancing the portfolio without losing alignment with the overall objectives of the company. Many companies obtain reasonable alignment between their technology portfolio and corporate strategies, though most struggle with obtaining an overall balance $e^{25}$. By including strategic alignment as a constraint in the model, the PMB could focus its efforts on finding the best overall balance within and across program stages while ensuring alignment with the long-term strategy. 
It should be noted that the model was created to support an established portfolio management process and not the reverse. The portfolio management process on the Airplane Creation Process Strategy program evolved over a period of several months. The addition of the Dependency Matrix and the Optimization Model was an extension of the process evolution. This enhanced the model's credibility because it was based on the data and metrics that were already in use. The analytical basis of the model can still lead to a false sense of precision. However, even with rough financial projections, the model is valuable as a means to compare alternate solutions.

The Dependency Matrix itself provided an unanticipated, but very powerful benefit. The discussions that occurred between Portfolio Management Board members during the development of the Dependency Matrix values were just as valuable as the finished matrix itself. Instead of dealing with the relationships and dependencies all at once like most graphical formats, each element of the matrix represents one side of the relationship between only two projects at a time. The matrix format facilitated the discussion of how the various projects related to one another and documented the results. The PMB members were able to quickly uncover and discuss their different perceptions of the interdependencies of the projects. In the future, the Dependency Matrix values should be supplied by the team submitting the project proposal (STP). This would facilitate the better integration of the projects before they enter the portfolio process and provide more cross-team integration during the development of project proposals.

\section{$\underline{\text { Potential Drawbacks }}$}

The mathematical nature of the model requires the input data to be numerically quantifiable. Many optimization models have been criticized in the past because they rely too heavily on financial data that are either not available or are not of high fidelity ${ }^{26}$. In the case of the ACPS program, the financial data were previously developed using a detailed financial model that had been validated and had credibility within the program. The minimum benefit values $\left(M_{i}\right)$ and the Dependency Matrix values $\left(d_{i}\right)$ were the only data created to support the model. 
Another criticism may be of the fidelity of the values populating the Dependency Matrix. The values of the minimum benefit level and the matrix do not have to be precise, but their relative ranges do have to be consistently applied. It is pointless for PMB members to argue over whether a particular element should be 0.98 or 0.95 . It does matter that they agree on the general magnitude and that the values within the matrix are judged on the same relative scale. The value of the Dependency Matrix occurs only when it is evaluated in aggregate.

There is also the tendency with mathematical models for the users to perceive a false sense of precision. The Portfolio Management Board did not succumb to this because they had already established the balance of the portfolio for Stage A before the Optimization Model was completed. The more typical reaction from the PMB when the model was first demonstrated was a realization at how much time they could save by having a valid, balanced starting point for the portfolio analysis. One board member commented, "The two scenarios you just solved for in five minutes took six of us eight hours to do on a Saturday." The model was perceived as a faster method of comparing alternate portfolios, not as a financial estimator for the program.

\section{Alternate Applications}

The Dependency Matrix was created to solve a particular problem at Boeing, though its simple form could easily be adapted for use in other types of models. The Dependency Matrix is useful in situations where a large number of elements are interdependent. The effect of the matrix can be either additive or subtractive. For example, on ACPS the effect subtracted from the project's potential if all supporting projects were not funded. By changing the Minimum Benefit Level to be a Maximum Benefit Level, the matrix's effect could add to the potential of a project if supporting projects are present.

A potential application of the matrix using a subtractive effect is the cannibalization of sales between products in a company's portfolio. The Dependency Matrix could quantify how one product cannibalizes the sales of other products already in a company's product line when 
their target markets overlap. Of course this would only provide the direction of the impact and its severity, but not account for the rate of the effect ${ }^{27}$.

There is also the possibility of using the Dependency Matrix to link research to products and products to markets as discussed in chapter 1 (see Mapping Portfolio Tools). This could be accomplished using multiple matrices. One matrix would relate technologies to each other. A second matrix would link the technologies to the products, and so on. In this case, the Optimization Model would connect the costs of the technologies to the benefits of the products. The model could also take care of the temporal effect of the life cycles involved in the technology and product development process.

The Optimization Model itself may not be directly applicable to other companies, though the general concept of the model might prove useful. The concept integrates numerous portfolio metrics, both quantitative and qualitative, into a single model. Integrating the metrics of an existing portfolio management process can be applied easily to other companies or situations. Furthermore, using a mathematical model as a scenario planning and sensitivity analysis tool that provides real-time results to the portfolio managers has proven beneficial.

\section{Conclusions}

From the perspective the ACPS program, the Dependency Matrix and the Optimization Model work together to enhance the portfolio management process. It provides a quick method to assess the balance of a portfolio as portrayed through the established PMB metrics.

The Dependency Matrix is a simple tool to document and quantify the interdependencies between projects. The values of the Dependency Matrix elements do not have to be precise, but the criteria for establishing the values must be consistently applied. The format of the matrix provides flexibility to add, remove or combine projects to conform to the decisions made during stage gate reviews. Finally, the process of populating the matrix can provide an 
effective forum for portfolio managers to discuss the interdependencies between projects and document the results.

The Optimization Model utilizes existing data, incorporates the aggregate effect of the Dependency Matrix, and integrates the existing portfolio management tools on the ACPS program. Using the optimal funding strategy as a starting point, the model's spreadsheet format provides flexibility to evaluate performance of alternative solutions. The performance of the portfolio is summarized in graphical formats similar to the PMB's existing portfolio management tools to simplify interpretation.

Dr. W. Edwards Deming summarized it best when he said, "All models are wrong. Some models are useful." The Dependency Matrix and the Optimization Model are not a magic bullet to solve the portfolio management process. They do provide additional tools to support the complex decision process to satisfy all three goals of portfolio management: maximize the value of the portfolio, provide balance, and support the strategy of the enterprise $e^{28}$. They effectively provide a means to optimize and balance interdependent projects over multiple time periods in a technology portfolio. 


\section{BIBLIOGRAPHY \& NOTES}

1 Rousel, P.K. Saad and T. Erickson. Thind Generation RED: Managing the Link to Conporate Strattegy, Boston, Massachusetts: Harvard Business School Press and Arthur D. Litrle Inc., 1991.

2 Cooper, RG., Edgett, S.J., Kleinschmidt, E.J., "Best Practices for Managing R\&D Portfolios," Researds \& Tedmology Management, July-August 1998.

${ }^{3}$ Cooper, R.G., Edgett, S.J., Kleinschmidt, E.J., "Portfolio Management in New Product Development: Lessons from the Leaders-I," Reseand \& T Tedmology Management, September-October 1997, pp 16-27

4 Cooper, R.G., Edgett, S.J., Kleinschmidt, E.J., "Portfolio Management in New Prochuct Development: Lessons from the Leaders-II," Reseando \& Tedmology Manazenent, November-December 1997, pp 43-52

${ }^{5}$ For a taxonomy of R\&\&D Project Selection and Resource Allocation research through 1990, see Hall, D.L, Nauda, A, "An Interactive Approach for Selecting IR\&D Projects," IEEE Transactions on Enginecring Managenents Vol. 37, No. 2, May 1990.

6 Cooper, R.G., Edgett, S.J., Kleinschmidt, E.J., Ponfolio Mamagement for New Products, Reading, Massachusetts: Perseus Books, 1998

7 Cooper, R.G., Edgett, S.J., Kleinschmidt, E.J., "Portfolio Management in New Product Development: Lessons from the Leaders-I," Researd \& Tedmology Manazement, September-October 1997, pp 16-27

${ }^{8}$ Cooper, R.G., Edgett, S.J., Kleinschmidt, E.J., Portyolio Managenent for New Products, Reading, Massachusetts: Perseus Books, 1998

${ }^{9}$ Cooper, R.G., Edgett, S.J., Kleinschmidt, E.]., Ponfolio Managenent for New Products, Reading, Massachusetts: Perseus Books, 1998

${ }_{10}$ Cooper, R.G., Edgett, S.J., Kleinschmid, E.J., "Porfolio Management in New Product Development: Lessons from the Leaders-I," Researd \& Tedmology Managenent, September-October 1997, pp 16-27

11 Groenveld, P, "Roadmapping Integrates Business and Technology," Reseand \& Tedmology Management, September-October 1997, pp 48-55

${ }_{12}$ Baker, N.R, "R\&DD Project Selection Models: an Assessment," IEEE Tramsactions on Engimeering Managemert, EM-21, 4, 1974, pp165-171.

${ }^{13}$ Danila, N., "Strategic Evaluation and Selection of R\&D Projects," $R E D$ Management, 19, 1, 1989, pp47-62

${ }_{14}$ Liberatore, M.J., "A Decision Support system Linking Research and Development Project Selection writh Business Strategy," Project Management Joamal, 19, 5, 1988, pp14-21

15 Cooper, R.G., Edgett, S.J., Kleinschmidt, E.J., "Portfolio Management in New Product Development: Lessons from the Leaders-I," Reseand \& Tedmology Managenent, September-October 1997, pp 16-27

${ }_{16}$ Cooper, R.G., Edgett, S.J., Kleinschmidt, E.J., Ponfolio Monagement for New Products, Reading, Massachusetts: Perseus Books, 1998

17 Cooper, R.G., Edgett, S.J., Kleinschmidt, E.J., "Portfolio Management in New Product Development: Lessons from the Leaders-II," Reseanch \& Tedmology Managemert, November-December 1997, PP 43-52

18 "Boeing doubts Airbus will build rival to 747," Seattle Tomes, February 5, 1996

19 "Airbus stands up for superjumbo," Seattle Tmes, Oatober 2, 1997

20 "Boeing is stretching its jets to offset Airbus superiumbo plans," Seattle Tomes, July 15, 1997

21 "Plans dropped for giant 747 jets," Seattle Tmes, January 21, 1997

22 Quoted from Boeing internal documents 
23 The Capability and Process Change Matrix was adapted from: Wheelwright, S.C., Clark, K.B., Reudutionizing Product Development: Quantum Leaps in Speed, Efficiency, and Quality, NY, NY: The Free Press, 1992

${ }^{24}$ Ulrich, K.T., Eppinger, S.D., Product Design and Development, McGraw-Hill, 1995

${ }_{25}$ Cooper, RG, Edgett, S.J., Kleinschmidt, E.J., "Best Practices for Managing R\&D Portfolios," Research \& Tednology Management, July-August 1998

${ }^{26}$ Cooper, R.G., Edgett, S.J., Kleinschmidr, E.J., "Portfolio Management in New Product Development: Lessons from the Leaders - I," Reseand \& Tednology Managenent, September-October 1997

${ }^{27}$ Cooper, RG., Edgett, S.J., Kleinschmidt, E.J., "Portfolio Management in New Product Development: Lessons from the Leaders - II," Research \& Tedmology Managenent, November-December 1997

${ }_{28}$ Cooper, R.G., Edgett, S.J., Kleinschmidt, E.J., "Ponfolio Management in New Product Development: Lessons from the Leaders-II," Reseand \& Tedmology Managenent, November-December 1997, pP 43-52

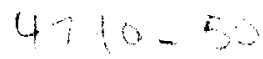

